Journal of Machine Engineering, 2020, Vol. 20, No. 2, 77-85

ISSN 1895-7595 (Print) ISSN 2391-8071 (Online)

Received: 02 August 2019 / Accepted: 02 October 2019 / Published online: 24 June 2020

titanium, titanium alloy, countermeasure against oxidation, L-ascorbic acid, machining

\author{
Ikuo TANABE ${ }^{1 *}$ \\ Yuya GOI ${ }^{1}$ \\ Yuko TANABE ${ }^{1}$
}

\title{
RESEARCH ON OXIDATION PHENOMENON DURING TITANIUM MACHINING AND ITS PREVENTION
}

\begin{abstract}
Over the last few decades, titanium alloys have become an important ingredient in many industrial sectors. In fact, titanium with additional characteristics, such as: high strength, heat resistance, low thermal conductivity, light weight and biocompatibility are being more and more used. However, the machining of titanium products tends to result in a thermal oxidation process and the development of a coloured layer. Therefore, a research regarding the thermal oxidation phenomena and its prevention was conducted. In this regard, cutting and grinding processes were experimentally investigated. Subsequently, L-ascorbic acid, a substance used against food oxidation, was used as an agent against oxidation during grinding. The main conclusions of the current study are the following: (1) Causes leading to the thermal oxidation during cutting and grinding were defined, (2) Prevention against oxidation was established by using L-ascorbic acid and strong alkaline water solution, (3) Optimum density of the solution with L-ascorbic acid and strong alkaline water was only $7.5 \mathrm{wt}$. \% for grinding.
\end{abstract}

\section{INTRODUCTION}

Over the last few decades, titanium alloys have become an important ingredient in many industrial sectors. In fact, the medical sector and the aerospace industry in particular benefited from these alloys. Actually, the aerospace industry found new limits to its designs [1], and a new generation of joint prosthesis and teeth implants reached the medical sector $[2,3]$. In this regard, titanium with additional characteristics, such as: high strength, heat resistance, low thermal conductivity, light weight and biocompatibility are frequently being used. In the same way, the latest industrial applications require the use of grinding and polishing processes to achieve a mirror-like surface finishing [4-6]. Nevertheless, machining titanium products presents a significant challenge, given that titanium tends to oxidize. Here, the oxidation process, regarded as "thermal oxidation phenomenon" [7-9], affects in a considerable way the surface roughness, accuracy and quality of the machined workpiece. Moreover, the presence of this phenomenon was also observed during the laser colouring process in which

\footnotetext{
${ }^{1}$ Nagaoka University of Technology, Department of Mechanical Engineering, Nagaoka, Japan

*E-mail: tanabeii@yahoo.co.jp https://doi.org/10.36897/jme/117758
} 
the oxidation is used to give the workpiece a certain colour [10]. As a result, countermeasures against the oxidation of titanium alloys are required to achieve high quality and high accuracy during conventional machining. The aim of this study is to develop a set of countermeasures against the thermal oxidation phenomena. The oxidation phenomenon was specifically analysed in two scenarios: the rough machining scenario, in the form of cutting, and the finish machining scenario, in the form of grinding. Subsequently, L-ascorbic acid, a substance used against food oxidation, was used as an agent against oxidation during grinding. Also, a solution of strong alkaline water and L-ascorbic acid was created and grinding was performed in this solution. The adequate solution density for grinding was defined after multiple experiments. Finally, titanium corrosion resistance in strong alkaline water with L-ascorbic acid was evaluated for a month.

\section{OXIDATION PHENOMENON DURING TITANIUM MACHINING}

The evaluation of the thermal oxidation phenomenon was conducted by considering two scenarios: the rough machining scenario, in the form of cutting, and the finish machining scenario, in the form of grinding.

\subsection{OXIDATION PHENOMENON DURING CUTTING}

Titanium alloys are considered as "difficult-to-machine" materials given their low thermal conductivity $\left(21.9 \mathrm{~W} / \mathrm{m}^{2} / \mathrm{K}\right)$. For this reason, most of the heat generation during machining tends to concentrate on the machining tool top, the tool tip ends up reaching temperatures up to $2000^{\circ} \mathrm{C}$ [11] and then melts. The titanium coloration changes to yellow or blue.

Therefore, in order to define the oxidation phenomenon during cutting the experimentation procedure was structured as follows: First, the cutting process was set to be turning with the cutting conditions shown in Table 1. Given an increasing speed and heat generation, the oxidation phenomenon that follows over the workpiece was evaluated using the X-ray fluorescence (XRF) analyser shown in Table 2.

Table 1. Cutting conditions used to observe the oxidation phenomenon

\begin{tabular}{|l|c|}
\hline \multicolumn{2}{|c|}{ Cutting conditions } \\
\hline Cutting speed & $24,39,71 \mathrm{~m} / \mathrm{min}$ \\
\hline Feed speed & $0.09 \mathrm{~mm} / \mathrm{rev}$ \\
\hline Depth of cut & $0.6 \mathrm{~mm}$ \\
\hline Work piece & Pure titanium (JIS type 2) \\
\hline Tool & $\begin{array}{c}\text { End mill with } 2 \text { throw away } \\
\text { tips (Tip: Rake angle } 5^{\circ} \\
\text { Coated, S30T) }\end{array}$ \\
\hline $\begin{array}{c}※ \text { Wet cutting done in strong alkaline water } \\
(\mathrm{pH} \mathrm{12.1)}\end{array}$ \\
\hline
\end{tabular}

Table 2. Specifications of the equipment used for measuring the oxygen X-ray spectrum and examination

\begin{tabular}{|l|c|}
\hline \multicolumn{2}{|c|}{ ZSX primus II } \\
\hline $\begin{array}{l}\text { Measurement } \\
\text { method }\end{array}$ & $\begin{array}{c}\text { Wavelength } \\
\text { dispersive }\end{array}$ \\
\hline $\begin{array}{l}\text { Elemental } \\
\text { coverage }\end{array}$ & ${ }_{4} \mathrm{Be}$ through ${ }_{92} \mathrm{U}$ \\
\hline $\begin{array}{l}\text { Measurement } \\
\text { object }\end{array}$ & Solid, liquid, gas \\
\hline Sample size & $\begin{array}{c}\varnothing 0.5-51 \mathrm{~mm}, \\
\text { maximum height } \\
30 \mathrm{~mm}\end{array}$ \\
\hline
\end{tabular}


Immediately after cutting, ultrasonic was cleaning of the workpiece performed and then the intensity of oxygen in the X-ray fluorescence spectrum was measured. Additionally, turning was performed using strong alkaline water $(\mathrm{pH}$ 12.1) [12] for cooling and as an oxidation countermeasure. As a result, the relationship between the XRF intensity of oxygen and the cutting speed is shown in Fig. 1; as well as the XRF intensity of oxygen regarding the material before the cutting was able performed. Here, it can be observed that dry and wet cutting did not generate a substantial oxidation. On the other hand, the surface roughness generated after cutting was obtained and shown in Fig. 2, and the measuring conditions were: the analysed length was $4 \mathrm{~mm}$, the accuracy was $0.001 \mu \mathrm{m}$ and the cut-off value was $0.8 \mathrm{~mm}$. Here it noted that even though different heat generated in each cutting, the roughness of all surfaces is remain same.

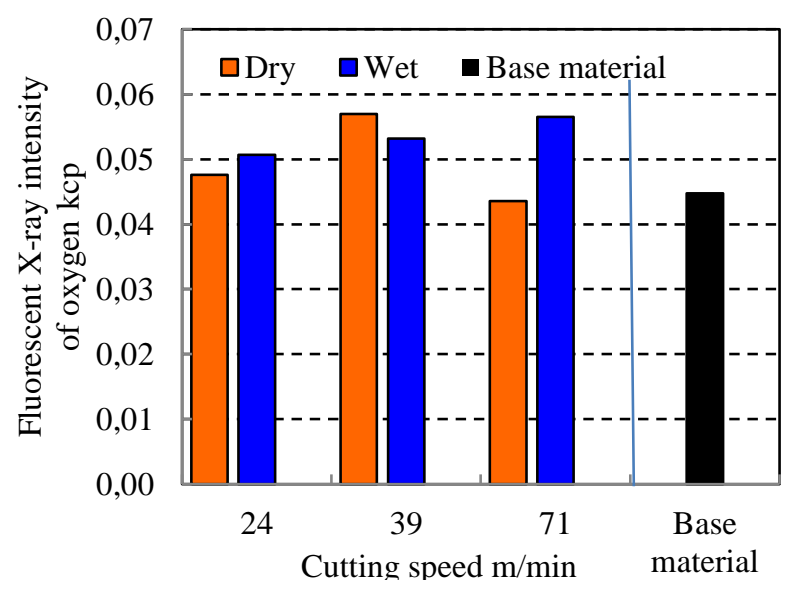

Fig. 1. Relationship between cutting speed and number of detected X-ray in the localized marks of thermal oxidation after the cutting experiments

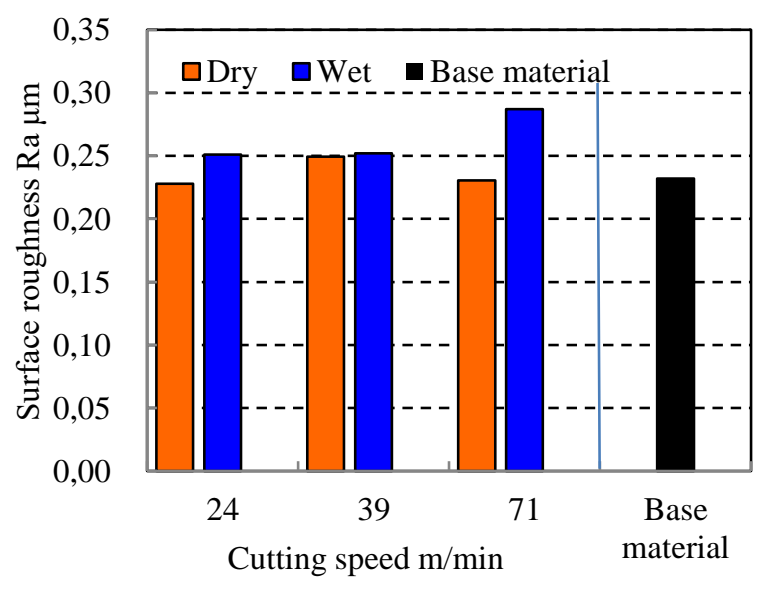

Fig. 2. Relationship between cutting speed and the surface roughness on the cutting surface during the cutting

In this matter, the reason for no evident thermal oxidation on the surface can be briefly explained. If the 2D cutting model shown in Fig. 3 is considered, the generated heat is composed of three different parts: $Q_{1}, Q_{2}$ and $Q_{3} ; Q_{1}$ is the heat generated due to the large plastic energy released on the shear surface between the workpiece and the chip, $Q_{2}$ is the heat generated due to the friction between the chip and the tool and $Q_{3}$ is the heat generated due to the friction between the chip and the tool. Both $Q_{1}$ and $Q_{3}$ directly influence the workpiece oxidation. However, the area $\mathrm{C}$ in Fig. 3 is immediately cut after heating in spite of the influence of $Q_{1}$, and when the abrasion of the tool is very little, $Q_{3}$ is negligible (nearly 0) [13].

On the other hand, chip photographs shown in Table 3. It can be seen that only the surface in contact with the tool's rake surface got oxidized and changed its colour. In contrast, the coloration in the opposite part of the chip did not change, arguably because of the titanium low thermal conductivity. Thus, the influence of $Q_{2}$ in Fig. 3 does not extend to the opposite surface of the chip.

Conclusively, as the focus of this section was the turning process and since there was no substantial evidence of thermal oxidation in either method of cutting, oxidation countermeasures are unnecessary in this specific process. 


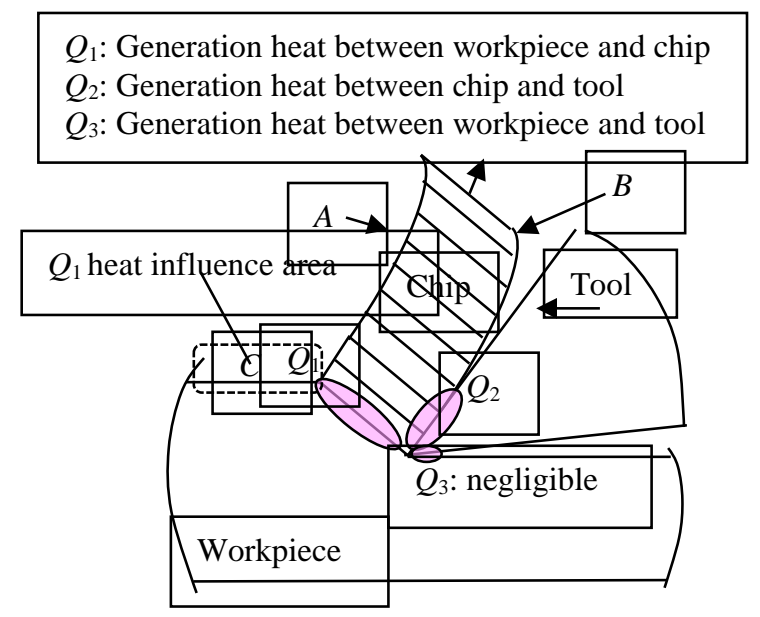

Table 3. Cutting conditions and chip photographs after experimentation

\begin{tabular}{|c|c|c|}
\hline Cutting speed & \multicolumn{2}{|c|}{$71 \mathrm{~m} / \mathrm{min}$} \\
\hline $\begin{array}{c}\text { Cutting } \\
\text { condition }\end{array}$ & \multicolumn{2}{|c|}{ Dry } \\
\hline Part of chip & A in Fig. 3 & B in Fig. 3 \\
\hline & & \\
Surface & & \\
condition & $100 \mu \mathrm{m}$ & $100 \mu \mathrm{m}$ \\
& & \\
& & \\
\hline
\end{tabular}

Fig. 3. Schematic view of generation heat on the cutting using $2 \mathrm{D}$-cutting model

\subsection{OXIDATION PHENOMENON DURING GRINDING}

This section presents, the oxidation phenomenon during grinding that analysed through multiple experiments. In this regard, a schematic view of the experimental set-up for the grinding of titanium is shown in Fig. 4, and the corresponding machining conditions are outlined in Table 4. The grinding speed was very low which is reasonable for low effects. The set-up consisted of a static high speed spindle over a mono-directional sliding table. In the same way, as the grinding speed increases, the generated heat is expected to increase and exhibit an oxidation phenomenon. This was evaluated using the same method of XRF intensity of oxygen as before. Moreover, wet grinding using strong alkaline water $(\mathrm{pH} 12.5)$ had both the cooling and oxidation countermeasure purpose. Immediately after grinding, ultrasonic cleaning of the workpiece was performed and then the fluorescent X-ray intensity of oxygen was measured.

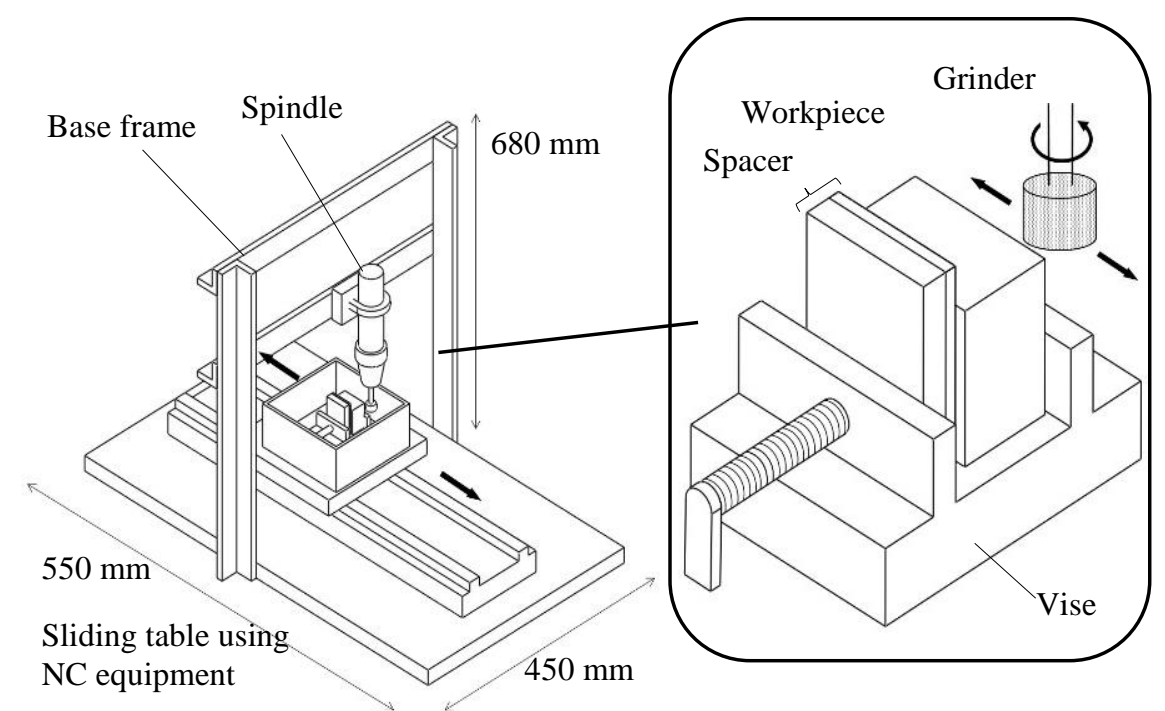

Fig. 4. Schematic view of experimental set-up for observing an oxidation reaction of titanium using grinding 
Table 4. Grinding conditions for the titanium oxidation reaction observation

\begin{tabular}{|l|l|}
\hline Spindle speed & $6,000 \sim 14,000 \mathrm{~min}^{-1}$ \\
\hline Grinding speed & $300,500,700 \mathrm{~m} / \mathrm{min}$ \\
\hline Feed speed & $1.8 \mathrm{~mm} / \mathrm{min}$ \\
\hline Grinding depth & $0.5 \mathrm{~mm}$ \\
\hline Workpiece & Pure titanium (JIS type 2) \\
\hline Grinding wheel & Material: WA, Bond: Vitrified, Grain size: \#80, Degree of bond: P \\
\hline \multicolumn{2}{|l}{ ※ In strong alkaline water $(\mathrm{pH} \mathrm{12.1)}$ at wet cutting } \\
\hline
\end{tabular}

The relationship between the fluorescent X-ray intensity of oxygen and the grinding speed is shown in Fig. 5. When the grinding speeds are $300 \mathrm{~m} / \mathrm{min}$ and $500 \mathrm{~m} / \mathrm{min}$, there is no evident thermal oxidation phenomenon on the machined surfaces; however, the fluorescent X-ray intensities of oxygen of these processes were larger than that of the previous cutting. Therefore, there was a substantial oxidation effect over the workpieces. Even more, when the grinding speed was $700 \mathrm{~m} / \mathrm{min}$, there was clear evidence of thermal oxidation phenomenon on the machined surfaces and the fluorescent X-ray intensity of oxygen of this sample was 2 times of those of the other grindings. Also, this oxidation behaviour occurred during wet grinding, simply because of the presence of oxygen in the water. In this regard, when the sample was analysed, surface marks had $\mathrm{TiO}_{2}$ present as a component.

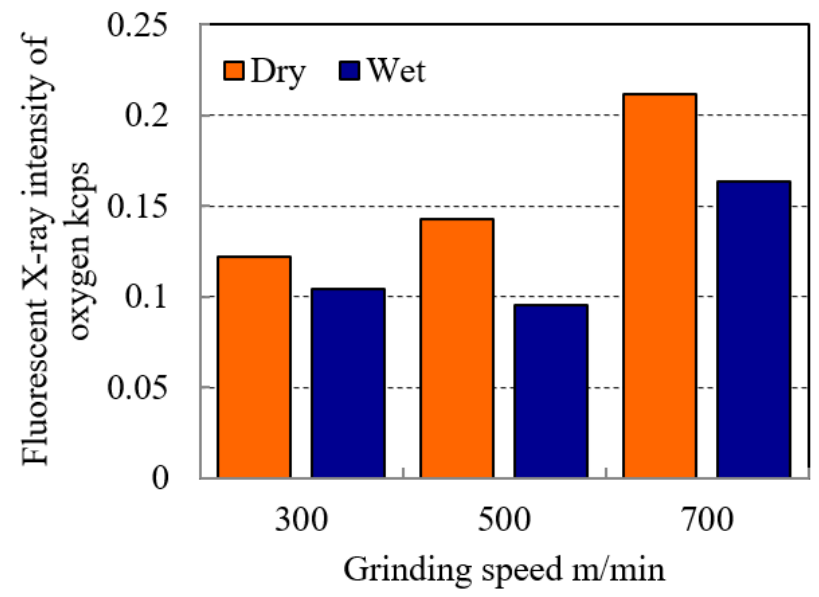

Fig. 5. Relationship between grinding speed and the number of detected X-ray in the localized marks of thermal oxidation after the cutting experiments

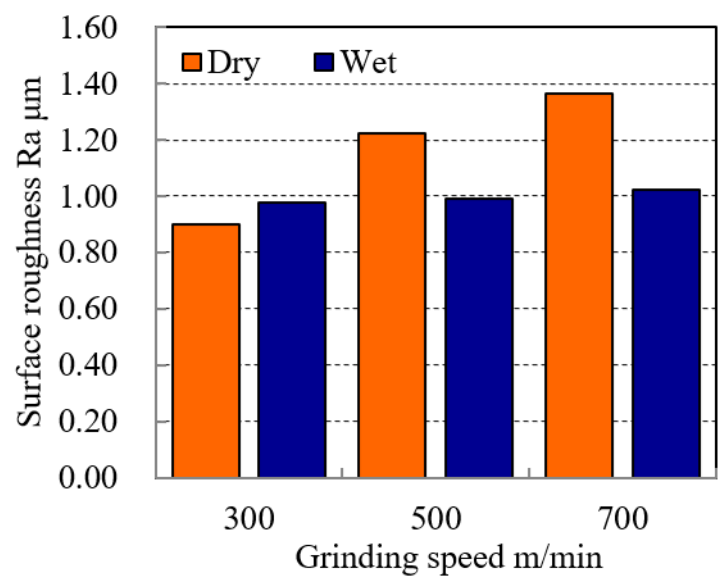

Fig. 6. Relationship between the grinding speed and the surface roughness of the grinding in the experiments

In addition, the surface roughness after grinding is shown in Fig. 6. In this case, the measurement conditions were: measuring length $4 \mathrm{~mm}$, accuracy $0.001 \mu \mathrm{m}$ and cut-off value $0.8 \mathrm{~mm}$. It was thought that when the grinding speeds increase, the surface roughness increases due to the presence of oxide elements in the surface. However, all the surface roughness measured after grinding had similar values disregarding the heat difference between the dry and the wet cuttings. Moreover, the reason for oxidation to occur on the surface after grinding is considered to be relatively simple. As shown in Fig. 7, on the front surface of a simplified grain, the generation heat for large plasticity energy occurs on the shear surface between the workpiece and the chip. The heat influence of this dissipates 
immediately and does not remain in the workpiece. However, on the both side surfaces of the grain, heat generation occurs due to the friction between the workpiece and the grain. In this case, it was thought that the heat generation remains on the workpiece and affects the oxidation phenomenon.

Friction surfaces between the grain and the workpiece

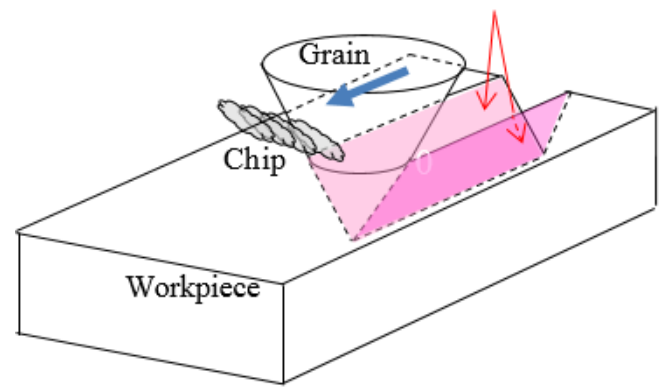

Fig. 7. Schematic view of a 3D-grinding model that describes the heat generation during grinding

Finally, photographs of workpiece surface grinding results are shown in Table 5. It can be observed that when the grinding speed increases gradually, the colour on the surface also changes and the grinding quality becomes worse. Conclusively, in grinding, the surfaces after dry and wet grindings were oxidized in the most grinding condition. Therefore, countermeasures against oxidation are necessary during grinding.

Table 5. Photographs of the workpiece oxidized surface after grinding

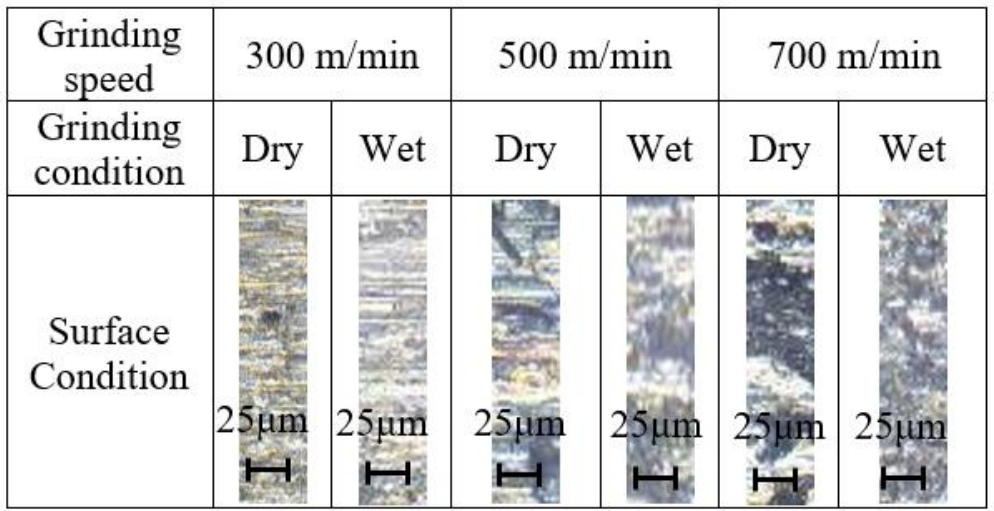

\section{APPLICATION OF L-ASCORBIC ACID AS A COUNTERMEASURE AGAINST OXIDATION}

Nowadays, there are few countermeasures against the thermal oxidation of titanium [14]. However, in the case of ultrashort pulse lasers, they are under powered, exhibit a high cost and inappropriate to be applied during machining. Inert gas could be used as a countermeasure against the oxidation of titanium; however, it exhibits a high cost and large amounts are required for its effectiveness. Moreover, nitrogen gas could be counterproductive as it could form titanium nitride in its interaction with titanium. 
In this research, L-ascorbic acid " $\mathrm{C}_{6} \mathrm{H}_{8} \mathrm{O}_{6}$ " was deemed to be appropriate as a countermeasure against the oxidation of titanium. L-ascorbic acid or vitamin $\mathrm{C}$ possess several positive properties, such as, a steady state, it can remove the oxygen in water, it is easily soluble in water and its aqueous solution is acidic $[15,16]$. In general, L-ascorbic acid is used for food additives, cosmetic and reducing agents because of its very high reduction force in the industry. Therefore, L-ascorbic acid was used in this research as an oxidation countermeasure. The experimental set-up for this section is shown in Fig. 4 and the titanium workpiece was submerged in the solution with strong alkaline water and L-ascorbic acid. The wet grinding was performed in a perfectly flooded condition. On the other hand, the grinding conditions are shown in Table 4, and the grinding speed is only $700 \mathrm{~m} / \mathrm{min}$.

Additionally, the relationship between the fluorescent X-ray intensity of oxygen and the grinding condition is shown in Fig. 8. The experimental parameters were dry grinding and wet grinding using strong alkaline water with $\mathrm{pH} 12.1$, wet grinding consisted in using a solution with $7.5 \mathrm{wt}$. \% of L-ascorbic acid in strong alkaline water with $\mathrm{pH} 12.1$. In this regard, it can be said that the L-ascorbic acid was an effective countermeasure for addressing the titanium oxidation.

The relationship between the fluorescent X-ray intensity of oxygen and the quantity of L-ascorbic acid is shown in Fig. 9. Here, it can be asserted from this that, as the quantity of L-ascorbic acid is gradually increased, the fluorescent X-ray intensity of oxygen decreases.

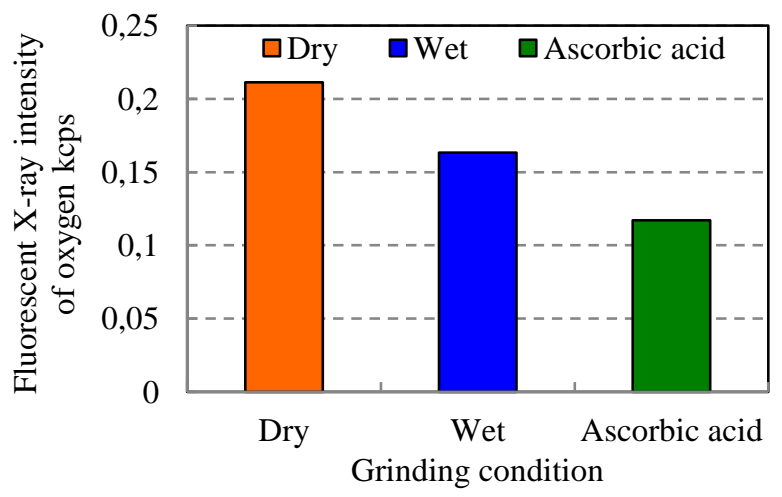

Fig. 8. Fluorescent X-ray intensity of oxygen using dry, wet and ascorbic acid wet grinding

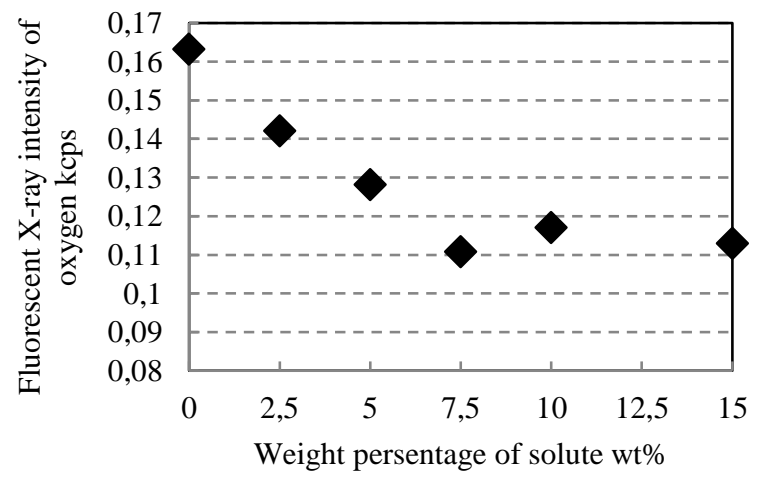

Fig. 9. Fluorescent X-ray analysis shows a decrease in oxygen following an increase in L-ascorbic acid. No major changes in oxygen when weight percentage of L-ascorbic acid is $7.5 \mathrm{wt}$. \% or more 
Thus, when the quantity of L-ascorbic is larger than the $7.5 \mathrm{wt} . \%$, it becomes steady. Thus, in this scenario, there was no thermal oxidation phenomena visible in the grinded surface. As mentioned above, $7.5 \mathrm{wt}$. \% of L-ascorbic acid was proposed as the optimum quantity to achieve an appropriate oxidation countermeasure.

\section{TITANIUM CORROSION RESISTANCE AGAINST A MIXTURE OF STRONG ALKALINE WATER AND L-ASCOBIC ACID}

A test to prove the corrosiveness of the developed mixture of L-ascorbic acid and alkaline water over titanium was performed for a time lapse of 1 month. In this regard, the experimental conditions for the corrosion resistance test are shown in Table 6. Specifically, a machined titanium workpiece was submerged for 1 month in a strong alkaline water ( $\mathrm{pH} 12.1)$ solution with $7.5 \mathrm{wt}$. \% of L-ascorbic acid at a room temperature of $20^{\circ} \mathrm{C}$ and $60 \%$ of humidity. There was no visible evidence of corrosion in the titanium surface as shown in Fig. 10; even more, no change in surface roughness was measured. Nevertheless, a XRF intensity of oxygen analysis was done before and after the corrosion resistance test, and as shown in Fig. 11, no considerable change was observed. Thus, it was concluded that the selected mixture was appropriate as a countermeasure against oxidation during the grinding of titanium alloys.

Table 6. Experimental conditions for corrosion resistance experiments

\begin{tabular}{|c|c|c|c|c|c|}
\hline \multicolumn{2}{|r|}{ Evaluation time } & 1 month & \multirow{4}{*}{ 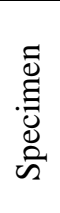 } & Material & Titanium (JIS Type 2) \\
\hline \multirow{3}{*}{$\begin{array}{l}\stackrel{\Xi}{\Xi} \\
\stackrel{\Xi}{\Xi} \\
\mathscr{S}\end{array}$} & Temperature of solution & $20 \pm 1^{\circ} \mathrm{C}$ & & Size & $20 \times 20 \times \mathrm{t} 1 \mathrm{~mm}$ \\
\hline & Ratio of L-ascorbic acid & 7.5 wt. $\%$ & & Surface roughness & $R z 0.55 \mu \mathrm{m}$ \\
\hline & Base & Strong alkaline water & & - & - \\
\hline
\end{tabular}

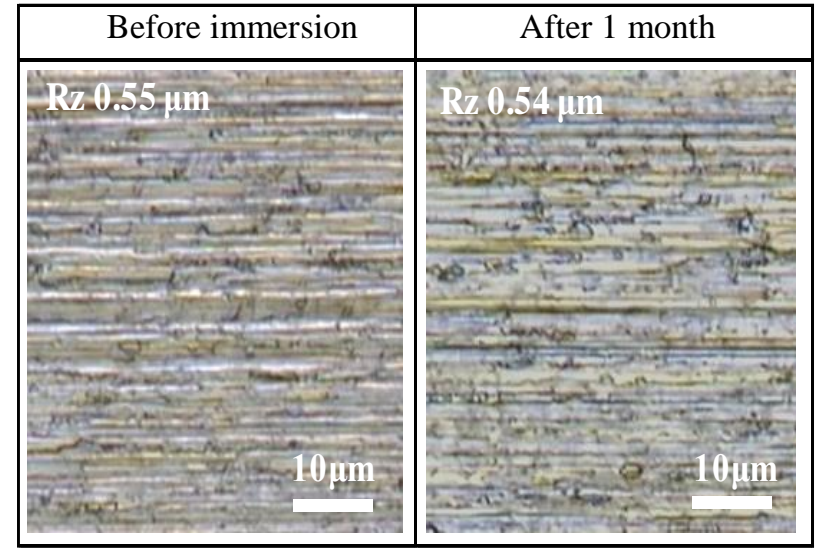

Fig. 10. Experimental results of corrosion resistance; although specimens were immersed in slurry including L-ascorbic acid, corrosion did not appear over the polished area

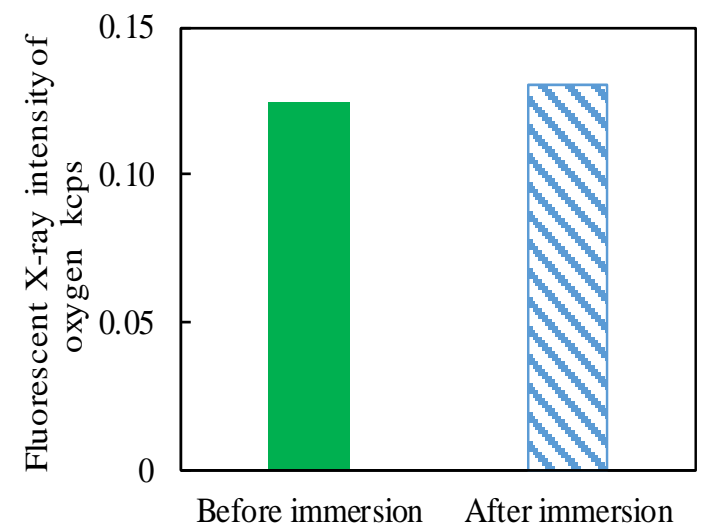

Fig. 11. Almost the same fluorescent X-ray intensity of oxygen was detected in a non-submerged specimen and a specimen immersed in slurry during 1 month 


\section{CONCLUSION}

This study leads to the following:

1. An understanding of the influence of thermal oxidation during cutting and grinding;

2. Oxidation countermeasures for the process of turning were deemed as unnecessary due to the absence of substantial evidence of thermal oxidation at different generations of heat;

3. The oxidation countermeasures were deemed necessary after finding the substantial evidence of thermal oxidation during dry and wet grinding performances;

4. Oxidation countermeasures were defined to be involving a mixture of L-ascorbic acid and strong alkaline water during the machining process;

5. The optimum density of the aforementioned mixture was deemed to be $7.5 \%$ for the grinding process;

6. The aforementioned mixture at 7.5 wt. $\%$ did not cause titanium to develop substantial corrosion.

\section{REFERENCES}

[1] NIINOMI M., 2004, Recenstrong Alkaline Waterplications, Research and Development in Titanium and Its Alloys, Tetsu-to-Hagane, 90/7, 462-471, (in Japanese).

[2] KOBAYASHI I., 2002, Titanium and Its Alloys as Biomaterials, Material Japan, 41/8, 553-560, (in Japanese).

[3] HANAWA T., 2012, Biocompatibility of Titanium-Favorable Properties, Journal of Japan Institute of Light Metals, 62/7, 85-290, (in Japanese).

[4] TANABE I., IYAMA T., AUNG L.M., KONDO R., 2010, High Speed Polishing for Large Die and Mold, Transactions of the Japan Society of Mechanical Engineers Series C, 76/772, 3822-3827, (in Japanese).

[5] TANABE I., KONDO T., INOUE Y., IYAMA T., 2011, High Speed and Fine Polishing Using Linear Motor, Transactions of the Japan Society of Mechanical Engineers Series C, 77/779, 2855-2862, (in Japanese).

[6] IYAMA T., TANABE I., 2011, Mirror-Like Finishing of Soft Materials Using a Polishing Tool with Controllable Hardness by Heat Softening, Transactions of the Japan Society of Mechanical Engineers Series C, 77/775, 1154-1160, (in Japanese).

[7] MIYAGAWA O., WATANABE K., OKAWA S., NAKANO S., SHIOKAWA N., KOBAYASHI M., TAMURA H., 1990, Grinding of Titanium Part2 Commercial Vitrified Wheels Made of Alumina Abrasives, The Journal of the Japanese Society for Dental Materials and Devices, 9/1, 45-52, (in Japanese).

[8] SOE Y.H., TANABE I., IYAMA T., HOANG T.B., 2010, Tool Technology to Reduce Cutting Heat Generation and Its Influences, Journal of Machine Engineering, 10/3, 5-16.

[9] SOE Y.H., TANABE I., IYAMA T., ABE Y., 2010, Control of Tool Temperature Using Neural Network for Machining Material with Low Thermal Conductivity, Journal of Machine Engineering, 10/3, 78-89.

[10] SHINADA M., TANABE I., SUGAI H., IYAMA T., 2007, Surface Treatment Regarding Coloring of Titanium Using Laser and Its Photocatalytic Effects, J. of Japan Institute of Light Metals, 73/726, 583-588, (in Japanese).

[11] TANABE I., IYAMA HOANG T.B., IYAMA T., KRATZ E., 2008, Development of New Electro Deposited Diamond Tool and Its Compulsory Cooling System for High Speed Grinding of Titanium and Nickel Alloys, Transactions of the Japan Society of Mechanical Engineers Series C, 74/747, 2797-2802, (in Japanese).

[12] TANABE I., JUNIOR R.D.C., SAKAGUCHI N., KANEKO Y., 2013, Development of Technology Regarding Soaking Machine Tool in Strong Alkaline Water for Reduction of $\mathrm{CO}_{2}$, Transactions of the Japan Society of Mechanical Engineers Series C, 79/797, DOI:10.1299/kikaic.79.67, (in Japanese).

[13] The Japan Society for Precision Engineering Ed., 1992, Handbook of Precision Machining, Corona publishing Co., Ltd, 25, (in Japanese).

[14] SAWADA H., 2006, Creation of Functional Surface by Using Femto-Second Laser, The Japan Society for Precision Engineering, 72/8, 951-954.

[15] Junsei Chemical Co., Ltd., 2001, Safety data sheets of L-ascorbic acid.

[16] HAYASI T., 1986, Chemistry of Ascorbic Acid and Its Utilization For Foods, Journal of the Japanese Society for Food Science and Technology, 33/6, 456-462, (in Japanese). 